\section{Welche Auswirkungen hat der Brexit auf die europäische Energie- und Klimapolitik?}

\author{
Die Brexit-Verhandlungen haben sich bisher überwiegend mit \\ anderen Themen befasst als mit der Energie- und Klimapolitik. \\ Es ist daher nicht leicht abzuschätzen, was der Brexit konkret \\ für die europäische Energie- und Klimapolitik bedeuten wird, \\ solange die Verhandlungen noch nicht abgeschlossen sind. \\ Von Rebecca Bertram
}

D ie Brexit-Verhandlungen erreichen Europa zu einem denkbar schlechten Zeitpunkt. Nirgends zeigt sich das so deutlich wie in der europäischen Energie- und Klimapolitik. Denn seit Ende 2016 diskutiert die Europäische Union darüber, wie sie sich bis 2030 klima- und energiepolitisch aufstellen will. Doch je nach EU-Mitgliedsstaat präsentiert sich die Energiewende anders, jeder verfolgt unterschiedliche nationale Ziele. Und gerade die Briten waren bisher einer der klimapolitisch progressivsten Mitgliedsstaaten und zugleich Künstler der Klimadiplomatie. Man kann nun auch erkennen, wie sich die Ungewissheiten des Brexits auf die Verhandlungen der 2030-Ziele auswirken: Großbritannien versucht gemeinsam mit dem Visegrad-Block die europäischen Energieund Klimapolitik aufzuweichen, um so den europäischen Zusammenhalt in den Brexit-Verhandlungen zu schwächen.

In zwei Bereichen der Energie- und Klimapolitik wird die EU den Weggang Großbritanniens besonders zu spüren bekommen.

\section{Herausforderung für die Dekarbonisierung}

Erstens werden die EU-weiten Dekarbonisierungsziele ohne Großbritannien schwieriger umzusetzen sein. Großbritannien hat sich zum Ziel gesetzt, seine nationalen Treibhausgasemissionen bis 2030 um 57 Prozent gegenüber 1990 zu verringern. Das nationale britische Klimaziel ist damit sehr viel ambitionierter als das europaweite 40-Prozent-Ziel, das gegenwärtig in der Europäischen Union verhandelt wird. Mit dem Weggang der Briten müssten die übrigen Europäer ihre Dekarbonisierungsambitionen erhöhen, um diesem Ziel zu entsprechen. Unter den gegenwärtig schwierigen politischen Umständen wäre das sehr unwahrscheinlich. Auch für das Europäische Emissionshandelssystem (ETS) hätte der Brexit schwerwiegende Folgen. Etwa 40 Prozent des britischen Reduktionsziels sollen durch den ETS-Mechanismus erreicht werden. Damit würde die internationale Glaubwürdigkeit des EU-Klimaziels für 2030 erheblich beschädigt. Denn nach dem Ausstieg der USA aus dem Pariser Abkommen kommt es umso mehr darauf an, dass andere große Staaten oder Staatengruppen ihre Verpflichtungen glaubhaft einhalten.

Zweitens hat der Brexit das Potenzial, den europäischen Strombinnenmarkt infrage zu stellen, dessen Teil Großbritannien ist. Zwischen Großbritannien und dem restlichen Europa besteht eine Konnektivitätskapazität von 4 Gigawatt ausgebaut werden sollte diese bis 2020 auf 12 Gigawatt. Der europäische Strombinnenmarkt bietet die nötige Flexibilität für die Eingliederung des europaweit steigenden Anteils an erneuerbaren Energien und wird deshalb für die europäischen Energie- und Effizienzziele zunehmend wichtig.
Würde Großbritannien mit dem Ausstieg aus der EU auch den Strombinnenmarkt verlassen, entfallen diese Flexibilitätsoptionen für den Rest Europas, die europäische Energiewende würde schwieriger und teurer werden. Außerdem wäre durch eine britische Aufkündigung des Strombinnenmarkts auch das EU-Land Irland betroffen, das Gas und Strom vom europäischen Festland oft über Großbritannien bezieht. Irlands Energiesicherheit wäre durch den Brexit gefährdet.

\section{Integrität des europäischen Strommarktes}

Großbritannien hat sich innerhalb Europas stets für Marktliberalität eingesetzt, und der liberalisierte europäische Energiemarkt ist vor allem auf das britische Engagement in den damaligen Verhandlungen zurückzuführen. Ein Weggang der Briten hätte zur Folge, dass die Rolle des Marktes als Gestaltungsmittel ambitionierter Klima- und Energiepolitik in der EU zurückgedrängt würde.

Es bleiben weiterhin viele Fragen offen zu den konkreten Auswirkungen des Brexits auf die europäische Energie- und Klimapolitik. Aber einige der Nachteile für beide Seiten sind schon jetzt sichtbar.

Ohne Großbritannien wird es für die EU noch schwieriger, ihre eigenen Klima- und Energieziele einzuhalten. Und für die Briten ist die EU sowohl bei der Erreichung ihrer Klimaziele als Teil des Europäischen Emissionshandelssystems als auch als Garant für Energiesicherheit von großer Bedeutung. Beide profitieren von einem kooperativen Ansatz. Ihn gilt es zu erhalten. Deshalb sollten sich EU und Großbritannien intensiv darum bemühen, dass der Brexit in diesem Bereich kein harter wird.

AUTORIN + KONTAKT

Rebecca Bertram ist Referentin für eine Europäische Energiewende bei der Heinrich-Böll-Stiftung

Heinrich-Böll-Stiftung, Schumannstraße 8 , 10117 Berlin. Tel.: +49 30 28534-352, E-Mail: Rebecca.Bertram@boell.de 